\title{
The exploration of the knowledge, attitudes and practice behaviors of advanced care planning and its related predictors among Taiwanese nurses
}

\author{
Chiu-Chu Hsieh ${ }^{1}$, Hsiang-Ping Huang ${ }^{2}$, Tao-Hsin Tung ${ }^{3}$, I-Chien Chen ${ }^{1}$, Randal D. Beaton ${ }^{4}$ and Sui-Whi Jane ${ }^{5,6^{*}}$ (D)
}

\begin{abstract}
Background: Despite the documented and well known patient benefits of ACP, the completion of ACP, only a minority of patients, during the advanced or EOL stage of their illnesses, receive such care. The misconceptions about ACP for healthcare providers, such as nurses, might become potential barriers to the effective implication of ACP. Also, from the transcultural perspective, it is evident essential to explore Taiwanese nurses' attitudes, knowledge, and actions of ACP. The purposes of this study were to explore the implication of ACP or hospice care for nurses caring for non-cancer chronic illness patients at a regional teaching hospital in Taiwan; and, to identify predictors of those nurses' knowledge, attitudes, and actions toward ACP.
\end{abstract}

Methods: This cross-sectional study with a purposive sample of 218 nurses was conducted at a teaching hospital in southern Taiwan. Structured questionnaires were employed and data were analyzed with descriptive statistics, t-test, one-way ANOVAs, Pearson's correlation and multiple regressions.

Results: $16.1 \%$ of Taiwanese physicians actively initiated ACP issues or conversations with patients or their family members. Nurses' attitudes toward ACP were fairly positive but their knowledge about ACP was insufficient and actions of ACP were not positively executed. The predictors of ACP-Knowledge (ACP-K) included position title, education hours and lacking of educational training. The predictors of ACP-Attitude (ACP-A) included ACP-K and "fear of patient or family member not accepting", whereas ACP-A, position title, "patients do not feel necessary" and "not sure physician's concern" were the predictors of ACP-Act.

Conclusion: Continuous education and training for nurses regarding ACP needs to be improved by taking those predictors found in this current study into account, and more studies on the nurse's role in ACP also should be further examined.

Trial registration: KAFGH 106-012. Date of registration 1 May 2017.

Keywords: Nurse, Advance care planning (ACP), Knowledge, Attitude, Practice behaviors

\footnotetext{
* Correspondence: swjane@gw.cgust.edu.tw

${ }^{+}$Hsiang-Ping Huang is equal contribution to the first author.

${ }^{5}$ Geriatric and Long-term Care Research Center, Graduate Institute of Nursing,

Chang Gung University of Science and Technology, 261, Wen-Hua 1st Rd.

Gui-Shan Dist, Tao-Yuan City 33303, Taiwan, Republic of China

${ }^{6}$ Division of Hematology/Oncology, Department of Internal Medicine, Chang

Gung Memorial Hospital, Lin-Ko, Taiwan, Republic of China

Full list of author information is available at the end of the article
}

(c) The Author(s). 2019 Open Access This article is distributed under the terms of the Creative Commons Attribution 4.0 International License (http://creativecommons.org/licenses/by/4.0/), which permits unrestricted use, distribution, and reproduction in any medium, provided you give appropriate credit to the original author(s) and the source, provide a link to the Creative Commons license, and indicate if changes were made. The Creative Commons Public Domain Dedication waiver (http://creativecommons.org/publicdomain/zero/1.0/) applies to the data made available in this article, unless otherwise stated. 


\section{Background}

Patients with chronic illnesses, despite progress in treating many chronic ailments, often may experience deterioration in their medical condition during the course of their illnesses. Palliative care, an emerging framework for improving the quality of end-of-life (EOL) care, embraces the active involvement of patients and their family members during the advanced and EOL stages of the illness and to manage the physical, psychosocial and spiritual components of their illness processes $[1,2]$. According to the National Consensus Project (NCP) [3], the ethical and legal aspects of advanced care planning (ACP) is one of important elements for palliative care. Over the past two decades, the essential implementation of ACP has shifted from providing advance directive (ADs) documents to enabling effective communication between patients and their caregivers regarding the provision of durable power of attorney for health care, preferences or goals of medical care, and treatment directives or living wills (i.e., do not resuscitate, DNR) [4]. Existing studies have shown that early palliative care or ACP improves patients' perceptions of progress [5], the efficacy of symptom management [6], enhances their quality of life and decreases the utilization of aggressive medical modalities and, importantly, undergirds patients' rights and supports their quality of dying [5]. Despite the documented and well known patient benefits of $\mathrm{ACP}$, the completion of ACP or related ADs, only a minority of patients, during the advanced or EOL stage of their illnesses, receive such care. For example, hospice care was reportedly provided for only $5-39 \%$ of such patients in the United States [7], 11\% in the United Kingdom [8] and 2.2\% in Taiwan [9]. Further, only 39\% of terminal patients in the US received hospice care, of which $35 \%$ of patients died in $7-14$ days $[10,11]$ or within 21 days [12]. Thirty-eight percent of patients were admitted to the intensive care unit within 10 days of their death [13]. Similarly, many patients signed their DNR document on the day of their death, and $95 \%$ of such DNR documents were signed for by their family members [14]. In Taiwan, a 2011 study found that only $13-17 \%$ of terminal cancer patients received hospice care; $17-19 \%$ of Taiwanese patients received hospice care 3 days before death [15], and a 2010 investigation found that up to $30 \%$ of Taiwanese patients continued to receive active emergency treatment at the EOL [16].

Clearly, a cohesive body of scientific evidence suggests there that are barriers to the effective implication of ACP, including medical personnel's misconceptions (i.e., ACP focuses only on moribund patients [4], the possibility that discussing ACP makes patients or their families uncomfortable or to lose hope [17], and that nurses do not need to participate in ACP [7]). Regarding the latter barrier, nurses are, in fact, the front line of clinical care and are the health provider in the best position to serve as promoters, messengers, and spokespeople facilitating discussions of ACP among healthcare teams, patients and their families $[7,17,18]$. Thus, the knowledge, attitudes, and behaviours of nurses toward ACP is crucial [19] for the successful implementation of ACP. But the accuracy of nurses or advanced practice nurses' (APN) knowledge on ACP was only 60\% [20]-67\% [21], respectively. In addition, other factors that hinder or promote nurses' effective communication with patients regarding ACP need to take into account, such as their age [8, 22], clinical experience [22], personal experience with ACP [7], and/or continuing education regarding ACP [23]. Other factors potentially influencing the implementation of ACP included lack of time to discuss ACP [24], excessive optimism by family members regarding the poor prognosis of the patient/family member [22], and uncertainty of physicians' concerns or actions of ACP [25].

To date, ACP-related studies primarily focussed on the effects related to the durable power of attorney, patients'/family members' perceptions/behaviours, or intensive care unit nurses' knowledge, attitudes, and behaviours toward ACP [5, 26]. Considering the leading causes of death in Taiwan, nurses, often have opportunities to take care of patients with chronic illness other than cancer. Therefore, exploration of Taiwanese nurses' knowledge and attitudes toward ACP while taking care for patients with chronic illnesses other than cancer are warranted.

The purposes of this study were to explore the implications of ACP or hospice care for nurses caring for patients with non-cancer chronic illnesses at a regional teaching hospital in Taiwan; and, to identify predictors of those nurses' knowledge, attitudes, and actions toward ACP.

\section{Methods \\ Study design and setting}

This descriptive, cross-sectional study with purposively sampling was conducted at a teaching hospital in southern Taiwan, Kaohsiung Armed Forces General Hospital (KAFGH), from December 2017 to February 2018. To be eligible for inclusion in the study, participants must have been registered nurses, had experience caring for non-cancer terminal patients and currently worked in internal medicine, general practice, or intensive care. Nurses who worked in departments with less terminal patients (e.g. orthopaedics, obstetrics \& gynaecology, psychiatry, surgery) were excluded from participation.

\section{Procedures}

This study was approved by the Kaohsiung Armed Forces General Hospital (KAFGH) Institutional Review Board (IRB \#106-012). Prospective participants received 
an explanation of the research purpose and procedure and were given an option to participate and informed of their rights. After obtaining written consent, the research associate provided participants with a battery of questionnaires and unsealed envelopes, and participants were asked to drop their sealed envelopes in collection boxes in their units upon completing the questionnaires.

\section{Instruments}

\section{Implication of hospice care and ACP (IHAC)}

A 6-item measure describing implication of hospice care and ACP used was primarily adapted from a 7-item measure at Zhou's study [21]. Four items with a Likert scale of 1 never to 5 always were to explore the implication of ACP, such as 'In my practice, the oncologist(s) initiates the discussion of ACP'. The fifth question asked participants to respond to the following statement: 'I estimate that the following percentages of patients receive hospice care prior to dying (i.e., within 2 weeks, 1 month of hospice referral)'. The sixth item was a multiple choice question with a list of 8 potential factors influencing nurses' discussion of ACP (based on the authors' clinical experience and literature review) such as 'lacking related training' or 'patients do not feel necessary'.

\section{Knowledge, attitude, and actions of ACP (KAAC-ACP)}

This 31-item measure used in this study to examine nurse participants' knowledge, attitudes, and actions of ACP and was adapted from a 34-item measure at Zhou's study [21]. The overall Cronbach $\alpha$ of this measure in Zhou's KAAC-ACP measure was $0.70-0.84$ with testretest reliability was 0.74 . The Cronbach $\alpha$ of KAACACP measure used in this current study was 0.80 .

\section{ACP-knowledge (ACP-K)}

The ACP-K used in the current study consisted of 9 items. Replies were scored 1 correct answer and 0 incorrect answers, higher scores indicating more accurate knowledge about ACP. The discrimination of ACP-K was 1 (fair) and the degree of difficulty was 0.5 (moderate level) in this current study based on the suggestions by Lee [27] and $\mathrm{Yu}$ [28]. According to the suggestion by Hsu, Hurng, \& Hungrng [29], Kuder-Richardson Formula 20 (KR-20) 0.374 was considered to be acceptable, thus, the KR-20 of 0.42 in this current study reached to an acceptable level.

\section{ACP-attitude (ACP-A)}

The ACP-A used to measure attitude toward ACP primarily adapted from Zhou's study [21], consisting of an 8-item ACP-A-b (belief, i.e., 'ACP discussion is very important for patients with life-threatening illnesses'), a 6item ACP-A-s (subjective standards, i.e., 'I believe it is my responsibility to discuss ACP with patients and families'), a 4-item ACP-A-p (perceived control, i.e., 'I feel confident in my ability to communicate 'bad news') with a Likert scale ranging from 1 (very much agree) to 5 (very much disagree). On this latter measure lower scores indicated more positive attitudes. The Cronbach's $\alpha$ of the ACP-A measure in this study was 0.73 .

\section{ACP-action (ACP-act)}

The subscale of KAAC-ACP used to measure ACP actions was 4-item ACP-Act (i.e., I routinely initiate ACP discussions with advanced cancer patients) with a Likert scale ranging from 1 , very much agree to 5 , very much disagree. Lower scores on this measure indicated more positive actions of ACP. The Cronbach's $\alpha$ of the ACPAct in this study was 0.86 .

\section{Demographic information and hospice-related education or experience}

Nurses' personal demographic information solicited in this study included their age, ethnicity, education, position, clinical ladder, and years of clinical practice experience. Nurses' hospice care or ACP-related information included completed hours of hospice/palliative continuing education, experience with taking care of patients with severe illnesses and whether they had experience taking care of family members with severe illnesses.

\section{Statistical analysis}

All statistical analyses were conducted using SPSS 20 software for Mac. Categorical variables were reported as well as frequency distribution and percentage, whereas continuous variables were reported as numerical values and standard deviations. Inferential analyses included Pearson correlation coefficients used to investigate the relationship between participants' knowledge, attitude, and actions of ACP and associated continuous factors; and simultaneous regressions model used to assess the independent effects of relevant factors on ACP values after controlling for the covariates. Sample size calculations were performed primarily depending on the regression analyses with $90 \%$ power, 11 independent variables, $10 \%$ variances, and 0.05 alpha, accounting for a total of 225 participants.

\section{Results}

\section{Sample characteristics}

Of the 225 distributed questionnaires, 221 were returned (98.2\% response rate) and the total sample consisted of 218 (98.6\% completion rate) with a mean age of 33.4 years $(\mathrm{SD}=8.0)$. The majority of participants were $\mathrm{N}$ or $\mathrm{N} 2$ nurses $(63 \%)$, university graduates $(73 \%)$, and the respondent sample's averaged years of clinical work experience was 10.8 years (their average years of service at the current institution was 5.8 years) (Table 1 ). 
Table 1 Demographic characteristics of the sample $(n=218)$

\begin{tabular}{|c|c|c|}
\hline Characteristics & $n(\%)$ & Mean \pm SD \\
\hline Age(years) ${ }^{a}$ & & $33.4 \pm 8.0$ \\
\hline $21 \sim 30$ & $92(42.2)$ & \\
\hline $31 \sim 40$ & $91(41.7)$ & \\
\hline $41 \sim 60$ & $35(16.1)$ & \\
\hline \multicolumn{3}{|l|}{ Ethnicity } \\
\hline Taiwanese & 200(91.7) & \\
\hline Mainlander & $8(3.7)$ & \\
\hline Hakka & $7(3.2)$ & \\
\hline Aborigine & $3(1.4)$ & \\
\hline \multicolumn{3}{|l|}{ Education } \\
\hline Junior college & $48(22.0)$ & \\
\hline University & 159(72.9) & \\
\hline Master or higher & $11(5.1)$ & \\
\hline \multicolumn{3}{|l|}{ Marital status } \\
\hline Single & $108(49.5)$ & \\
\hline Married & 102(46.8) & \\
\hline Divorced & $8(3.7)$ & \\
\hline \multicolumn{3}{|l|}{ Religion } \\
\hline None & $71(32.6)$ & \\
\hline Buddhism /Taoism & $121(55.5)$ & \\
\hline other & 26(11.9) & \\
\hline \multicolumn{3}{|l|}{ Department } \\
\hline ICU & $84(38.5)$ & \\
\hline Medical Unit & $61(28.0)$ & \\
\hline Mixed Unit & $46(21.1)$ & \\
\hline Surgical Unit & $27(12.4)$ & \\
\hline \multicolumn{3}{|l|}{ Position Title } \\
\hline Registered Nurse & $201(92.2)$ & \\
\hline Assistant head nurse & $7(3.2)$ & \\
\hline Head Nurse & $10(4.6)$ & \\
\hline \multicolumn{3}{|l|}{ Clinical ladder ${ }^{a}$} \\
\hline N & $77(35.3)$ & \\
\hline $\mathrm{N} 1$ & $55(25.2)$ & \\
\hline N2 & $60(27.5)$ & \\
\hline N3 \& N4 & 26(11.9) & \\
\hline Years of work experience ${ }^{b}$ & & $10.8 \pm 8.4$ \\
\hline 3 years below & 45(20.6) & \\
\hline 3 years and higher & 173(79.4) & \\
\hline \multicolumn{3}{|c|}{ Hours of Palliative continuous education } \\
\hline $0-6 h$ & 175(81.0) & \\
\hline $7-12 h$ & $31(14.2)$ & \\
\hline $13-21 \mathrm{~h}$ & $10(4.7)$ & \\
\hline \multicolumn{3}{|l|}{ Hospice-related certification } \\
\hline Basic or advanced training & $13(6.0)$ & \\
\hline
\end{tabular}

Table 1 Demographic characteristics of the sample $(n=218)$ (Continued)

\begin{tabular}{lcc}
\hline Characteristics & $n(\%)$ & Mean \pm SD \\
\hline None & $205(94.0)$ & \\
Have ever serious illness & $23(10.6)$ \\
Yes & $195(89.4)$ \\
No & $8(3.7)$ \\
Have signed palliative care directs document \\
Yes & $210(96.3)$ \\
No & $81(37.2)$ \\
Have experience of taking family members with end-stage illness \\
Yes & $137(62.8)$ \\
No
\end{tabular}

Note: a: According to the years of professional seniority, the registered nurses are classified as four clinical ladders, including $\mathrm{N}$ (within 1 year of clinical experience), $\mathrm{N} 1$ (1 year of clinical experience), N2(2 years of clinical experience), $\mathrm{N} 3$ (3 years of clinical experience), \& N4(4 years of clinical experience) in Taiwan; b: Mean \pm SD

\section{Implication of hospice care and ACP (IHAC)}

The implication of hospice care and ACP (IHAC) was evaluated with four items with 1 (never) to 5 (always), and the score of 3 (sometimes) was used as a cut-off point for further comparisons. In this study, there was $16.1 \%$ of physicians often or always initiating discussion of ACP with patients $(p=0.007)$ or $13.3 \%$ of terminal patients would often or always discuss ACP with their physicians $(p=0.001)$. The difference between "sometimes" and "seldom" frequency of terminal patients receiving critical care in the last month of life was not significant $(p=0.255)$, indicating that the frequency was moderate compared to often or seldom responses. In contrast, terminal patients received relatively frequent hospice care in clinical practice $(p=0.001)$ (Table 2$)$. In addition, the most common timing of hospice referral prior to dying was within 2 weeks (32.3\%), followed by within 1 month (26.8\%), 3 months (20.3\%), and 6 months (16.8\%).The frequency of potential factors influencing nurses' discussion of ACP are given in the Table 3.

\section{Knowledge, attitude, and ACP actions (KAAC-ACP)}

The mean score of the 9-item ACP-Knowledge was 4.74 $(\mathrm{SD}=1.36)$, with an accuracy rate of $52.7 \%(50 \%$ as a cut-off point indicated in Zhou's study). By using the cut-off point of 3 for each item as neutral responses (total score $3 * 19=57$ points), the mean score of the three subscales of ACP-Attitude, including ACP belief, subjective standard, and perceived control ranged from 1.81 to 3.72 and the total scores were $48.26(p<0.001)$. Similarly, using the cut-off points of 3 for each item as neutral responses (total score $3 * 4=12$ ), the total score of the 3-item ACP-Act was $11.92(p=0.651)$. The mean score of the item with 'I will routinely discuss ACP with 
Table 2 The Implications of Hospice and Advanced Care Planning (ACP) $(n=218)$

\begin{tabular}{|c|c|c|c|c|c|c|c|c|}
\hline Questions & $\begin{array}{l}\text { Never } \\
n(\%)\end{array}$ & $\begin{array}{l}\text { Seldom } \\
n(\%)\end{array}$ & $\begin{array}{l}\text { Sometimes } \\
n(\%)\end{array}$ & $\begin{array}{l}\text { Often } \\
n(\%)\end{array}$ & $\begin{array}{l}\text { Always } \\
n(\%)\end{array}$ & $\mathrm{M} \pm \mathrm{SD}$ & $t$ & $p$ value \\
\hline 1. In clinical practice, physician____ discuss ACP actively & $4(1.8)$ & $56(25.7)$ & $123(56.4)$ & $34(15.6)$ & $1(0.5)$ & $2.87 \pm 0.70$ & -2.708 & 0.007 \\
\hline $\begin{array}{l}\text { 2. In my estimation, about __ } \% \text { of EOL patients have discussed ACP } \\
\text { with clinicians in clinical practice }\end{array}$ & $1(0.5)$ & 74(33.9) & $114(52.3)$ & 28(12.8) & $1(0.5)$ & $2.79 \pm 0.68$ & -4.583 & $<0.001$ \\
\hline $\begin{array}{l}\text { 3. In my estimation, about } \\
\text { critical care during the last month of their lives in clinical practice }\end{array}$ & $3(1.4)$ & 75(34.4) & $84(38.5)$ & $46(21.1)$ & $10(4.6)$ & $2.93 \pm 0.89$ & -1.141 & 0.255 \\
\hline $\begin{array}{l}\text { 4. In my estimation, about __ } \% \text { of EOL patients received hospice } \\
\text { care in clinical practice }\end{array}$ & $1(0.5)$ & $33(15.1)$ & 118(54.1) & 63(28.9) & $3(1.4)$ & $3.16 \pm 0.70$ & 3.284 & 0.001 \\
\hline
\end{tabular}

Note: EOL, end of life; these four questions were assessed with a Likert scale of 1 never to 5 always

end-of-life (EOL) patients' or 'I will discuss ACP with over half of EOL patients' was 3.19 and 3.21 (both $p<0.001$ ), respectively, However, there was positive agreement on 'I will follow up ACP for EOL patients' $(p<0.001)$.

\section{Predictors of knowledge, attitude, and ACP actions for nurses}

The results from Pearson correlation coefficient among knowledge, attitude, and ACP actions, documented a negative correlation between ACP-K and ACP-A ( $p=$ $0.002)$, but no significant correlation between ACP-K and ACP-Action $(p=0.69)$. In contrast, there was significant correlation between overall ACP-A and ACPAction $(p<0.001)$ and the ACP-A-p (perceived control) had the strongest correlation with ACP-Action $(p<$ $0.001)$ followed by ACP-A-s (subjective standard) $(p<$ 0.001 ) and ACP-A-b (belief) $p=0.002$ ). For those significant correlated variables were identified for the simultaneous regression analyses.

According to the significant differences of participants' characteristics and ACP-K (Tables 4 \& 5), there were seven potential predictors, such as age, position, and lacking related training, accounting for variance of R2 15.9\% (Adjusted R2 12.3\%). Furthermore, results from regression analyses found that the knowledge of 'head nurses' was greater than that of 'nurses' $(p=0.001)$, the level of knowledge of nurses with '7-12 palliative

Table 3 Potential factors influencing nurses' discussion of ACP $(n=218)$

\begin{tabular}{|c|c|}
\hline Items & $n(\%)$ \\
\hline $\begin{array}{l}\text { Worry of patient or family member being misinterpreted of } \\
\text { giving up }\end{array}$ & $121(55.8)$ \\
\hline Worry of patient or family not accepting & $99(45.6)$ \\
\hline Unsure of physician's concerns & $76(35.0)$ \\
\hline Not sure when is the best timing to discuss & $76(35.0)$ \\
\hline Lacking related training & $68(31.3)$ \\
\hline Not familiar to the content of ACP & $60(27.6)$ \\
\hline Do not know how to communicate with patient or family & $55(25.3)$ \\
\hline Patients do not feel necessary & $39(18.0)$ \\
\hline
\end{tabular}

Note: Multiple choices continuous education' was lower than that with ' $0-6 \mathrm{~h}$ ' $(p=0.002)$, and the knowledge level of those who believed they had 'lacking related training' was lower than those who did not believe they were lacking relevant training $(p=0.014)$ (Table 6).

Four potential predictors of ACP-Attitude included ACP-K, 'patients do not feel necessary', 'not sure when is the best timing to discuss', and 'Worry of patient or family not accepting' (Tables 4 \& 5) accounted for variance of R2 9.4\% (Adjusted R2 7.7\%). Of which ACP-K and 'Worry of patient or family not accepting' was found to have significant explanatory power, indicating participants with higher $\mathrm{ACP}-\mathrm{K}$ and lower ACP-A had more positive attitudes $(p=0.002)$ (Table 6$)$. Those who selfreported 'Worry of patient or family not accepting' and had higher scores for ACP-A also had more negative attitudes $(p=0.042)$.

In terms of potential predictors for ACP-Action, ten potential predictors found and are shown in Tables 4 \& 5 and in the regression analyses, accounted for variance of R2 63.8\% (Adjusted R2 37.5\%). Six of ten variables had significant variances, such as ACP-A-b $(p=0.0001)$, ACP-A-s $(p=0.001)$, ACP-A-p $(p=0.012)$, position $(p=$ $0.046)$, 'patients do not feel necessary' $(p=0.044)$, 'unsure of physician's concerns' $(p=0.014)$ (Table 6). In this model, three subscales of ACP-A become more positive, ACP-Action was more likely to be positive, i.e., 'Assistant head nurses' scored lower on ACP-Action than 'nurses', that is, their ACP-Action was more positive.

\section{Discussion}

This descriptive study is apparently first to explore the implications of ACP, Taiwanese nurses' knowledge, attitude, actions of ACP, and some of its predictors. The results of this study indicated that $16.1 \%$ of physicians actively initiated ACP conversation with patients or their family members. Numerous patients approaching EOL stage would likely rarely or never received hospice care; still, some patients received critical care during the last month of their lives. In addition, nurses' attitude toward ACP was positive, but their knowledge about ACP and their actions of ACP as measured were suboptimal. In 
Table 4 The differences of nurses' characteristics and knowledge, attitudes, and actions of Advanced Care Planning (ACP) ( $n=218)$

\begin{tabular}{|c|c|c|c|c|c|c|c|c|c|}
\hline \multirow[t]{2}{*}{ Variables } & \multicolumn{3}{|c|}{ ACP-Knowledge } & \multicolumn{3}{|l|}{ ACP-Attitude } & \multicolumn{3}{|l|}{ ACP-Action } \\
\hline & $\mathrm{M} \pm \mathrm{SD}$ & $F$ & Scheffe's test & $\mathrm{M} \pm \mathrm{SD}$ & $F$ & Scheffe's test & $\mathrm{M} \pm \mathrm{SD}$ & $F$ & Scheffe's test \\
\hline \multicolumn{10}{|l|}{ Age } \\
\hline $21 \sim 30(n=92)$ & $4.47 \pm 1.35$ & $3.58^{*}$ & - & $48.94 \pm 5.96$ & 0.8 & & $12.12 \pm 2.52$ & 1.34 & \\
\hline $31 \sim 40(n=91)$ & $4.90 \pm 1.31$ & & & $47.85 \pm 6.87$ & & & $11.97 \pm 2.88$ & & \\
\hline $41 \sim 60(n=35)$ & $5.03 \pm 1.15$ & & & $47.54 \pm 6.84$ & & & $11.26 \pm 2.59$ & & \\
\hline \multicolumn{10}{|l|}{ Position title } \\
\hline $\mathrm{RN}^{\mathrm{a}}(n=201)$ & $4.67 \pm 1.31$ & $6.83^{* *}$ & $\mathrm{HN}>\mathrm{RN}$ & $48.44 \pm 6.54$ & 1.06 & & $12.03 \pm 2.70$ & $3.17^{*}$ & - \\
\hline $\mathrm{AHN}^{\mathrm{b}}(n=7)$ & $4.57 \pm 0.79$ & & $\mathrm{HN}>\mathrm{AHN}$ & $45.86 \pm 7.56$ & & & $9.57 \pm 2.15$ & & \\
\hline $\mathrm{HN}^{\mathrm{C}}(n=10)$ & $6.20 \pm 0.92$ & & & $46.20 \pm 4.37$ & & & $11.30 \pm 1.95$ & & \\
\hline \multicolumn{10}{|l|}{ Clinical ladder } \\
\hline $\mathrm{N}^{\mathrm{d}}(n=77)$ & $4.49 \pm 1.37$ & $3.37^{*}$ & $\mathrm{~N} 2>\mathrm{N}$ & $48.87 \pm 5.96$ & 1.05 & & $12.14 \pm 2.63$ & 0.56 & \\
\hline $\mathrm{N} 1^{\mathrm{e}}(n=55)$ & $4.65 \pm 1.27$ & & & $48.62 \pm 7.05$ & & & $11.95 \pm 3.00$ & & \\
\hline $\mathrm{N} 2^{f}(\mathrm{and})$ above $(n=86)$ & $5.01 \pm 1.26$ & & & $47.48 \pm 6.58$ & & & $11.70 \pm 2.54$ & & \\
\hline \multicolumn{10}{|l|}{ Years of work experience } \\
\hline$<5$ years $(n=72)$ & $4.46 \pm 1.32$ & $4.96^{*}$ & & $48.92 \pm 5.89$ & 1.11 & & $12.40 \pm 2.58$ & 3.55 & \\
\hline$>=5$ years $(n=146)$ & $4.88 \pm 1.30$ & & & $47.93 \pm 6.77$ & & & $11.68 \pm 2.72$ & & \\
\hline \multicolumn{4}{|c|}{ Palliative continuous education } & & & $0 \sim 6 h>$ & & & \\
\hline $0 \sim 6 \mathrm{~h}(n=175)$ & $4.87 \pm 1.26$ & $4.47^{*}$ & $0 \sim 6 h>$ & $48.44 \pm 6.22$ & $3.62^{*}$ & $13 \sim 21 \mathrm{~h}$ & $12.02 \pm 2.66$ & 0.82 & \\
\hline $7-12 \mathrm{~h}((n=31)$ & $4.19 \pm 1.64$ & & $7-12 \mathrm{~h}$ & $49.06 \pm 7.54$ & & $7-12 h>$ & $11.68 \pm 2.44$ & & \\
\hline $13-21 \mathrm{~h}((n=10)$ & $4.25 \pm 0.62$ & & & $43.50 \pm 6.14$ & & $13 \sim 21 \mathrm{~h}$ & $11.08 \pm 3.66$ & & \\
\hline
\end{tabular}

a: $R N$ registered nurse, b: $A H N$ assistant head nurse, c: $H N$ head nurse, d: nurses' working experience within 1 year; e: nurses' clinical competency at level I defined by Taiwan Nurses Association (can fulfill patients' basic care); f: nurses' clinical competency at level II defined by Taiwan Nurses Association (can offer advanced or critical care patients care); ${ }^{*} p<0.05,{ }^{* *} p<0.01$

terms of predictors of ACP, the most significant factors included position title and hours of hospice continuing education for knowledge of ACP; level of knowledge and worry of family not accepting for attitude of ACP; and position tile, ACP belief, subjective standard, and perceived control, "unsure of the physician's concerns about ACP", and "patients do not feel that ACP actions were necessary" for actions toward ACP.

From a methodological perspective, the selection of a reliable and valid measure is considered to be crucial, especially for a survey study. The measure used to examine nurses' nurses' knowledge, attitudes, and actions of ACP in this current study was adapted from a measurement development study by Zhou [21]. The results from Zhou' s study indicated that a 34-item measure regarding nurses' knowledge, attitudes and practice behaviors ACP demonstrated fair construct validity and test-retest reliability. Considering the limited studies in the area of ACP for nurses available, thus, the results of this current study would be primarily compared to results from Zhou's study.

The majority of nurses in this study reported that physicians occasionally initiated discussions of ACP in their clinical practice, and that the frequency of discussion of ACP with terminal patients was lower than that reported
Zhou et al. [21]. In addition, 54\% of nurses in the current study believed that terminal patients sometimes received hospice care, but that $63 \%$ of such patients died within 2 weeks to 1 month after referral to hospice care, and $65 \%$ of nurses believe that terminal patients sometimes (or often) or always received treatment in the intensive care unit within month before death. These results parallel those of Zhou et al. [21], who reported that $62 \%$ of their respondents believed that fewer than $50 \%$ of patients received hospice care, $47 \%$ believed that $50-95 \%$ of patients died within 2 weeks of referral to hospice care, and the majority of respondents believed that over $50 \%$ of cancer patients underwent chemotherapy sometime within the last month of life. In addition, NHPCO [30] show that $39 \%$ of decedents in the United States received hospice care and that $35 \%$ of cases died within 7 days of referral. From these data one could make the argument that the timing of referral to hospice care in both the United States and Taiwan is laggard.

The overall ACP-K correct response rate of $53 \%$ in this study, indicating that nurses' knowledge about ACP was prone to be at a moderate level and was lower than that reported by Ryan \& Jezewski (68-71\% with different measure) [20] and most nurses believed that ADs can effectively communicate patients' wishes for EOF care. 
Table 5 The influencing factors for nurses' knowledge, attitude, and actions of Advanced Care Planning (ACP) $(n=218)$

\begin{tabular}{|c|c|c|c|c|c|c|c|c|c|}
\hline \multirow[t]{2}{*}{ Variables } & \multicolumn{3}{|c|}{ ACP-Knowledge } & \multicolumn{3}{|l|}{ ACP-Attitude } & \multicolumn{3}{|l|}{ ACP-Action } \\
\hline & $\mathrm{M} \pm \mathrm{SD}$ & $t$ & $p$ value & $\mathrm{M} \pm \mathrm{SD}$ & $t$ & $p$ value & $\mathrm{M} \pm \mathrm{SD}$ & $t$ & $p$ value \\
\hline \multicolumn{10}{|c|}{ Lacking related training } \\
\hline $\operatorname{yes}(n=68)$ & $4.43 \pm 1.21$ & 2.382 & 0.018 & $49.34 \pm 6.74$ & -1.662 & 0.098 & $2.43 \pm 2.79$ & -1.893 & 0.060 \\
\hline $\mathrm{No}(n=150)$ & $4.88 \pm 1.34$ & & & $47.77 \pm 6.04$ & & & $11.69 \pm 2.62$ & & \\
\hline \multicolumn{10}{|c|}{ Not familiar with the content of ACP } \\
\hline $\operatorname{yes}(n=60)$ & $4.50 \pm 1.28$ & 1.655 & 0.099 & $48.32 \pm 6.65$ & -0.084 & 0.933 & $12.80 \pm 2.39$ & -3.043 & 0.003 \\
\hline $\mathrm{No}(n=158)$ & $4.83 \pm 1.32$ & & & $48.20 \pm 6.46$ & & & $11.58 \pm 2.73$ & & \\
\hline \multicolumn{10}{|c|}{ Patients do not feel necessary } \\
\hline yes $(n=39)$ & $4.90 \pm 1.10$ & -0.831 & 0.407 & $46.90 \pm 6.28$ & 2.001 & 0.047 & $10.77 \pm 2.79$ & 2.997 & 0.003 \\
\hline $\mathrm{No}(n=179)$ & $4.70 \pm 1.36$ & & & $48.70 \pm 6.48$ & & & $12.17 \pm 2.61$ & & \\
\hline \multicolumn{10}{|c|}{ Unsure of physician's concerns } \\
\hline $\operatorname{yes}(n=76)$ & $4.91 \pm 1.27$ & -1.442 & 0.151 & $48.30 \pm 6.12$ & -0.202 & 0.984 & $12.47 \pm 2.74$ & -2.190 & 0.030 \\
\hline $\mathrm{No}(n=142)$ & $4.64 \pm 1.34$ & & & $48.28 \pm 6.00$ & & & $11.65 \pm 2.62$ & & \\
\hline \multicolumn{10}{|c|}{ Not sure when is the best timing to discuss } \\
\hline $\operatorname{yes}(n=76)$ & $4.61 \pm 1.35$ & 1.094 & 0.275 & $49.53 \pm 6.43$ & -2.219 & 0.034 & $12.33 \pm 2.84$ & -1.660 & 0.098 \\
\hline $\mathrm{No}(n=142)$ & $4.81 \pm 1.30$ & & & $47.58 \pm 6.45$ & & & $11.50 \pm 2.59$ & & \\
\hline \multicolumn{10}{|c|}{ Do not know how to communicate with patient or family } \\
\hline $\operatorname{yes}(n=55)$ & $4.44 \pm 1.30$ & 1.982 & 0.049 & $49.09 \pm 5.924$ & 1.102 & 0.272 & $12.91 \pm 2.72$ & 3.232 & 0.001 \\
\hline $\mathrm{No}(n=163)$ & $4.84 \pm 1.30$ & & & $7.98 \pm 6.67$ & & & $11.58 \pm 2.60$ & & \\
\hline \multicolumn{10}{|c|}{ Worry of patient or family not accepting } \\
\hline $\operatorname{yes}(n=99)$ & $4.82 \pm 1.34$ & -0.814 & 0.416 & $49.22 \pm 6.19$ & -2.016 & 0.045 & $12.56 \pm 2.49$ & -3.267 & 0.001 \\
\hline $\mathrm{No}(n=119)$ & $4.67 \pm 1.30$ & & & $47.45 \pm 6.66$ & & & $11.39 \pm 2.74$ & & \\
\hline \multicolumn{10}{|c|}{ Worry of patient or family being misinterpreted of giving up } \\
\hline Yes $(n=97)$ & $4.78 \pm 1.29$ & -0.479 & 0.632 & $48.57 \pm 6.22$ & -0.795 & 0.427 & $12.27 \pm 2.49$ & -2.146 & 0.033 \\
\hline $\mathrm{No}(n=121)$ & $4.69 \pm 1.36$ & & & $47.87 \pm 6.84$ & & & $11.49 \pm 2.88$ & & \\
\hline
\end{tabular}

The correct response rate in this study was far lower at 8.3-37.6\%, whereas it was $69-81 \%$ in Zhou's study [21]. As mentioned earlier, only having ADs on the medical record without actual conversations with patients cannot ensure that the patient's wishes are met [31]. This difference might be due to the fact that the Patient Autonomy Act in Taiwan has not yet been implemented [32], so awareness of health care proxies in the ACP implementation process among nurses is not yet well recognized.

The results of ACP-A indicated that nurses' attitudes toward to ACP were prone to be positive (total scores were 48.26 over 57 ). Overall, nurses agreed with the importance of ACP (ACP-Ab), but do not fully believe that patients in the EOL require ACP. In addition, nurses were mostly positive about 'patients want to discuss their own treatment and care' (ACP-A-s), but were not certain of their responsibility in ACP. This result was similar to that of Izumi [4], who found that over $40 \%$ of nurses indicated that they had never participated in ACP and the main reason was that they did not think ACP was their responsibility. Nurses reported significantly more negative attitudes on ACP-A-p in this study and far more negative than a previous study [21]. In particular, nurses in the current study indicated that they were uncomfortable discussing ACP issues with terminal patients, due to their lack of knowledge and confidence. This discrepancy may be because the above mentioned study [21] interviewed APNs, whose clinical role and function differed from those of the nurses in the present study. Another explanation might be related to the dynamics of healthcare team in Taiwan where physicians, more often, are the most informed to make decisions, so nurses feel inappropriate when they want to discuss ACP with patients.

The overall ACP-Act of the nurses in the present study was neutral (total score was 11.92 over 12), but they were less likely to initiate ACP discussion compared to the previous study [21]. However, they were more able to routinely follow up ACP discussions. This might have reflected the nurses' negative attitudes reported on ACPA-s (ACP is a professional responsibility for nurses), indicating that nurses may be less likely to engage in routine 
Table 6 The predicting factors of knowledge, attitude, and action of Advanced Care Planning (ACP) for nurses $(n=218)$

\begin{tabular}{|c|c|c|c|c|c|c|c|}
\hline & \multicolumn{2}{|c|}{ unstandardized coefficients } & \multirow[t]{2}{*}{ Beta } & \multirow[t]{2}{*}{$t$} & \multirow[t]{2}{*}{$p$ value } & \multicolumn{2}{|l|}{ Collinearity } \\
\hline & $B$ & SE & & & & Tolerance & VIF \\
\hline \multicolumn{8}{|l|}{ ACP-Knowledge } \\
\hline (constant) & 4.807 & 0.174 & & 27.67 & 0.000 & & \\
\hline Age & 0.018 & 0.037 & 0.106 & 0.474 & 0.636 & 0.079 & 12.621 \\
\hline \multicolumn{8}{|l|}{ Position title } \\
\hline \multicolumn{8}{|l|}{$\mathrm{RN}^{\mathrm{a}}\left(\right.$ ref $\left.^{\mathrm{d}}\right)$} \\
\hline $\mathrm{AHN}^{\mathrm{b}}$ & -0.296 & 0.495 & -0.040 & -0.598 & 0.551 & 0.917 & 1.091 \\
\hline $\mathrm{HN}^{\mathrm{c}}$ & 1.367 & 0.421 & 0.218 & 3.248 & 0.001 & 0.899 & 1.112 \\
\hline \multicolumn{8}{|l|}{ Clinical ladder } \\
\hline \multicolumn{8}{|l|}{$N\left(\right.$ ref $\left.^{d}\right)$} \\
\hline N1 & 0.045 & 0.235 & 0.015 & 0.192 & 0.848 & 0.672 & 1.489 \\
\hline N2(and)above & 0.272 & 0.283 & 0.101 & 0.962 & 0.337 & 0.366 & 2.735 \\
\hline Years of work experience & 0.009 & 0.015 & 0.060 & 0.644 & 0.520 & 0.465 & 2.152 \\
\hline \multicolumn{8}{|c|}{ Palliative continuing education } \\
\hline \multicolumn{8}{|l|}{$0 \sim 6 \mathrm{~h}\left(\mathrm{ref}^{\mathrm{d}}\right)$} \\
\hline $7 \sim 12 \mathrm{~h}$ & -0.774 & 0.247 & -0.206 & -3.131 & 0.002 & 0.936 & 1.069 \\
\hline$>12 \mathrm{~h}$ & -0.651 & 0.375 & -0.113 & -1.735 & 0.084 & 0.954 & 1.048 \\
\hline \multicolumn{8}{|l|}{ lacking related training } \\
\hline \multicolumn{8}{|l|}{ No(ref $\left.{ }^{d}\right)$} \\
\hline Yes & -0.457 & 0.183 & -0.161 & -2.490 & 0.014 & 0.966 & 1.035 \\
\hline \multicolumn{8}{|c|}{ Do not know how to communicate with patient or family } \\
\hline \multicolumn{8}{|l|}{ No(ref $\left.{ }^{d}\right)$} \\
\hline Yes & -0.211 & 0.201 & -0.070 & -1.049 & 0.295 & 0.917 & 1.090 \\
\hline \multicolumn{8}{|l|}{ ACP-Attitude } \\
\hline (constant) & 51.966 & 1.664 & & 31.231 & 0.000 & & \\
\hline ACP-Knowledge & -0.994 & 0.324 & -0.202 & -3.072 & 0.002 & 0.987 & 1.013 \\
\hline \multicolumn{8}{|c|}{ patients do not feel necessary } \\
\hline \multicolumn{8}{|l|}{ No(ref $\left.{ }^{d}\right)$} \\
\hline Yes & -2.015 & 1.105 & -0.119 & -1.823 & 0.070 & 0.995 & 1.005 \\
\hline \multicolumn{8}{|c|}{ Not sure when is the best timing to discuss } \\
\hline \multicolumn{8}{|l|}{$\mathrm{No}\left(\mathrm{ref}^{\mathrm{d}}\right)$} \\
\hline Yes & 1.639 & 0.891 & 0.121 & 1.839 & 0.067 & 0.989 & 1.011 \\
\hline \multicolumn{8}{|c|}{ Worry of patient or family not accepting } \\
\hline \multicolumn{8}{|l|}{$\mathrm{No}\left(\mathrm{ref}^{\mathrm{d}}\right)$} \\
\hline Yes & 1.744 & 0.853 & 0.134 & 2.045 & 0.042 & 0.990 & 1.010 \\
\hline ACP-Action & & & & & & & \\
\hline (constant) & 1.097 & 1.176 & & 0.933 & 0.352 & & \\
\hline$A C P-A-b^{e}$ & 0.382 & 0.062 & 0.367 & 6.188 & 0.000 & 0.820 & 1.220 \\
\hline ACP-A-S ${ }^{f}$ & 0.161 & 0.047 & 0.202 & 3.452 & 0.001 & 0.838 & 1.193 \\
\hline ACP-A-p ${ }^{g}$ & 0.110 & 0.043 & 0.146 & 2.547 & 0.012 & 0.876 & 1.141 \\
\hline Position title & & & & & & & \\
\hline $\mathrm{RN}^{\mathrm{A}}\left(\mathrm{ref}^{\mathrm{d}}\right)$ & & & & & & & \\
\hline$A H N^{b}$ & -1.689 & 0.840 & -0.111 & -2.011 & 0.046 & 0.945 & 1.058 \\
\hline $\mathrm{HN}^{\mathrm{c}}$ & -0.121 & 0.707 & -0.009 & -0.171 & 0.864 & 0.948 & 1.055 \\
\hline
\end{tabular}


Table 6 The predicting factors of knowledge, attitude, and action of Advanced Care Planning (ACP) for nurses ( $n=218)$ (Continued)

\begin{tabular}{|c|c|c|c|c|c|c|c|}
\hline & \multicolumn{2}{|c|}{ unstandardized coefficients } & \multirow[t]{2}{*}{ Beta } & \multirow[t]{2}{*}{$t$} & \multirow[t]{2}{*}{$p$ value } & \multicolumn{2}{|l|}{ Collinearity } \\
\hline & $B$ & SE & & & & Tolerance & VIF \\
\hline \multicolumn{8}{|c|}{ Not familiar to the content of ACP } \\
\hline \multicolumn{8}{|c|}{ No(ref $\left.{ }^{d}\right)$} \\
\hline Yes & 0.581 & 0.339 & 0.097 & 1.715 & 0.088 & 0.904 & 1.107 \\
\hline \multicolumn{8}{|c|}{ Patients do not feel necessary } \\
\hline \multicolumn{8}{|c|}{ No(ref $\left.{ }^{d}\right)$} \\
\hline Yes & -0.792 & 0.390 & -0.113 & -2.030 & 0.044 & 0.926 & 1.080 \\
\hline \multicolumn{8}{|c|}{ Unsure of physician's concern } \\
\hline \multicolumn{8}{|c|}{ No(ref $\left.{ }^{d}\right)$} \\
\hline Yes & 0.748 & 0.302 & 0.136 & 2.478 & 0.014 & 0.951 & 1.052 \\
\hline \multicolumn{8}{|c|}{ Do not know how to communicate with patient or family } \\
\hline \multicolumn{8}{|c|}{ No(ref $\left.{ }^{d}\right)$} \\
\hline Yes & 0.559 & 0.348 & 0.091 & 1.606 & 0.110 & 0.907 & 1.103 \\
\hline \multicolumn{8}{|c|}{ Worry of patient or family not accepting } \\
\hline \multicolumn{8}{|c|}{$\mathrm{No}\left(\mathrm{ref}^{\mathrm{d}}\right)$} \\
\hline Yes & 0.435 & 0.306 & 0.081 & 1.423 & 0.156 & 0.894 & 1.119 \\
\hline \multicolumn{8}{|c|}{ Worry of patient or family being misinterpreted of giving up } \\
\hline \multicolumn{8}{|c|}{ No(ref $\left.{ }^{d}\right)$} \\
\hline Yes & 0.344 & 0.304 & 0.064 & 1.130 & 0.260 & 0.905 & 1.105 \\
\hline
\end{tabular}

a: $R N$ registered nurse, b: $A H N$ assistant head nurse, c: $H N$ head nurse, d: ref reference group, e: $A C P-A-b$ ACP-Attitude-belief, f: $A C P$ - $A$-s ACP-Attitude-subjective standard, g: ACP-A-p ACP-Attitude-perceived control

or active discussion with respect to implementation behaviour, but they are willing to cooperate and participate in the work of tracking ACP. It might be beneficial to use real-life simulation teaching methods in the form of role playing or case studies to enhance the effectiveness of ACP training [33, 34]. In addition, Taiwan is scheduled to implement the Patient Autonomy Law in January 2019 [32] to educate either general publics or healthcare providers to establish $\mathrm{ADs}$ and designate medical surrogates early, enhancing the awareness and acceptance of ACP and reducing the resistance by physicians and nurses.

Various predictors of knowledge, attitude, and action for ACP were found in our sample. For example, ACPKnowledge predictors, 'position title' and 'lacking related training' of nurses had significant predictive power, and the knowledge of head nurses was significantly greater on the measure use than that of nurses. Because head nurses are more experienced and had policy-driven responsibilities, it is not surprising that they have a more knowledge of ACP compared to line nurses. Factors affecting ACP-A include ACP-K and 'worry of patient or family not accepting'. As ACP-K increases, ACP-A becomes more positive. This result was consistent with the literature [19], which found that increasing the knowledge of nurses was beneficial to their willingness to promote ACP. Those who reportedly 'worry of patient or family not accepting' had more negative ACP-A, potentially crating an obstacle to their implementations of ACP. In addition, the present study found that the ACP-Act of assistant head nurses was significantly greater than that of nurses $(p=0.046)$. Yet, there were no differences between head nurses and nurses $(p=$ 0.864). This may be due to the fact that the work of head nurses in Taiwan is more concerned with administrative issues than with frontline patient care, whereas assistant head nurses are usually more experienced than nurses, have more work experience, and are thus more able to implement ACP. This finding was similar to those reported by Black \& Emmet [35] and Shepherd [36], which found that clinical experience, personal experience with ADs, and communication skills affected nurses' implementation of ACP. That investigation also found that older nurses and those with more experience had higher levels of participation in ACP.

\section{Conclusion}

Most of the nurses in the present study believed that it was uncommon for physicians to initiate discussions of $\mathrm{ACP}$ in clinical practice, with $65 \%$ of respondents indicating that terminal patients continue to receive treatment in intensive care units within 1 month prior to death. In addition, the nurses in our study reported that $63 \%$ of patients died within 2 weeks to 1 month after referral to hospice care. Although the nurse respondents in our study 
reported positive attitudes toward $\mathrm{ACP}$, their knowledge about ACP was suboptimal and the practice of behaviours in ACP discussion was, in our judgment insufficiently proactive. Also, 11 predictors affecting nurses' knowledge, attitudes, or actions of ACP were identified in this study. In the future, we recommend providing nurses with the onthe-job ACP training program based on those affecting predictors and using situational teaching or case discussion to strengthen nurses' awareness and communication abilities for ACP professional duties. More importantly, we recommend that nurses practice in accordance with the Taiwanese national policy of promoting the significance of ADs and medical surrogates in the Patient $\mathrm{Au}$ tonomy Act to improve physicians' recognition of nurses' roles in supporting the implementation of ACP, so that the nurses can more confidently play a role in $\mathrm{ACP}$ promotion.

\section{Limitations}

Despite some of impressive findings of the nurses' knowledge, attitudes, and actions toward ACP in this study, any interpretation of this study should consider a number of study limitations. Firstly, the study population is selected on a voluntary basis. The potential nurses not only would potentially introduce selection bias, but also Hawthorne effect is inevitable due to the subjects made a conscious decision to be in the selected hospitals. Secondly, we did not evaluated all the related wards, who might have characteristics that differ from those of the study population, that is, the generalization and external validity should be further discussed. Thirdly, this crosssectional study obtained measures at a single time point, which might not reflect long-term exposure to the participants' factors related ACP. Finally, this study was conducted at one regional teaching hospital in southern Taiwan, indicating that no generalizations could be made beyond this hospital in Taiwan and so not for Taiwan itself or wider still globally. Therefore, future investigations with a wider range of regions would make the results more discursive.

\section{Acknowledgements}

This research was partially supported by an intramural fund from Administration Center of Medical Research Department, Chang Gung Memorial Hospital (CGMH), Taiwan (BMRP 900). A special thank goes to Kaohsiung Armed Forces General Hospital for their administrative support and assistance. The authors gratefully acknowledge all 218 participants for their time and effort contributed to this study. There are no financial relationships that might lead to a conflict of interest.

\section{Authors' contributions}

$\mathrm{SJ}, \mathrm{CH}$, and $\Pi \mathrm{T}$ contributed to the development of research design and protocol. $\mathrm{CH}$ and IC conducted the collection and preliminary analyses of the data. $\mathrm{HH}, \mathrm{TT}$ and RD confirmed results and discussion sections. SJ, CH, $\mathrm{HP}$ and $T$ drafted the initial manuscript and RB refined and edited this manuscript. All authors contributed to the development of the manuscript and approved the final version.

\section{Funding}

This research was partially supported by intramural fund from Administration Center of Medical Research Department, Chang Gung Memorial Hospital (CGMH), Taiwan (BMRP 900). This study protocol was peer reviewed by the advisory committee of graduate program at Chang Gung University of Science and Technology. The funding institution did not influence the design of the study, collection, analysis or interpretation of data, and writing of the manuscript.

Availability of data and materials

All datasets during and/or analyzed during this study are available from the corresponding author on reasonable request.

Ethics approval and consent to participate

This study was approved by the Taiwan Kaohsiung Armed Forces General Hospital (KAFGH) Institutional Review Board (IRB \#106-012).

\section{Consent for publication}

This manuscript does not contain any specific individual's data.

\section{Competing interests}

The authors declare that they have no competing interests.

\section{Author details}

${ }^{1}$ Department of Nursing, Kaohsiung Armed Forces General Hospital, Kaohsiung, Taiwan, Republic of China. ${ }^{2}$ Department of Nursing, Chang Gung University of Science and Technology, Tao-Yuan, Taiwan, Republic of China. ${ }^{3}$ Department of Medical Research and Education, Cheng Hsin General Hospital, Taipei, Taiwan, Republic of China. ${ }^{4}$ Psychosocial \& Community Health and Health Services, Schools of Nursing and Public Health, University of Washington, Seattle, USA. ${ }^{5}$ Geriatric and Long-term Care Research Center, Graduate Institute of Nursing, Chang Gung University of Science and Technology, 261, Wen-Hua 1st Rd., Gui-Shan Dist, Tao-Yuan City 33303, Taiwan, Republic of China. ${ }^{6}$ Division of Hematology/Oncology, Department of Internal Medicine, Chang Gung Memorial Hospital, Lin-Ko, Taiwan, Republic of China.

Received: 13 March 2019 Accepted: 30 October 2019

Published online: 11 November 2019

\section{References}

1. Sepulveda C, Marlin A, Yoshida T, Ullrich A. Palliative care: the World Health Organization's global perspective. J Pain Symptom Manag. 2002;24(2):91-6.

2. Hines S, McCrow J, Abbey J, Foottit J, Wilson J, Franklin S, et al. The effectiveness and appropriateness of a palliative approach to care for people with advanced dementia: a systematic review. JBI library of systematic reviews. 2011;9(26):960-1131.

3. Ferris FD, Bruera E, Cherny N, Cummings C, Currow D, Dudgeon D, et al. Palliative cancer care a decade later: accomplishments, the need, next steps -- from the American Society of Clinical Oncology. J Clin Oncol. 2009;27(18): 3052-8.

4. Izumi S. Advance care planning: the Nurse's role. Am J Nurs. 2017; 117(6):56-61

5. Brinkman-Stoppelenburg A, Rietjens JA, van der Heide A. The effects of advance care planning on end-of-life care: a systematic review. Palliat Med. 2014;28(8):1000-25.

6. Jacobsen J, Jackson V, Dahlin C, Greer J, Perez-Cruz P, Billings JA, et al. Components of early outpatient palliative care consultation in patients with metastatic nonsmall cell lung cancer. J Palliat Med. 2011;14(4):459-64.

7. Splendore E, Grant C. A nurse practitioner-led community workshop: increasing adult participation in advance care planning. J Am Assoc Nurse Pract. 2017:29(9):535-42

8. Frank C, Heyland DK, Chen B, Farquhar D, Myers K, Iwaasa K. Determining resuscitation preferences of elderly inpatients: a review of the literature. CMAJ. 2003;169(8):795-9

9. Welfare MoHa. Rate of the Hospice Palliative Care \& Life-Sustaining Treatment Advance Care Plan signed in Health insurance card 2016 [updated 2017/05/11; cited 2018 11/28]. Available from: https://www.mohw. gov.tw/cp-2632-14712-1.html. 
10. Hui D, Elsayem A, De la Cruz M, Berger A, Zhukovsky DS, Palla S, et al. Availability and integration of palliative care at US cancer centers. Jama. 2010;303(11):1054-61.

11. Bruera E, Hui D. Conceptual models for integrating palliative care at cancer centers. J Palliat Med. 2012;15(11):1261-9.

12. Hui $D$, Parsons $H$, Nguyen $L$, Palla SL, Yennurajalingam $S$, Kurzrock $R$, et al. Timing of palliative care referral and symptom burden in phase 1 cancer patients: a retrospective cohort study. Cancer. 2010;116(18):4402-9.

13. Gorman TE, Ahern SP, Wiseman J, Skrobik Y. Residents' end-of-life decision making with adult hospitalized patients: a review of the literature. Acad Med. 2005;80(7):622-33.

14. Levin T, Li Y, Weiner JS, Lewis F, Bartell A, Piercy J, et al. How do-notresuscitate orders are utilized in cancer patients: timing relative to death and communication-training implications. Palliat Support Care. 2008;6(4):341-8

15. Tang ST, Huang EW, Liu TW, Wang HM, Rau KM, Chen JS. Aggressive endof-life care significantly influenced propensity for hospice enrollment within the last three days of life for Taiwanese cancer decedents. J Pain Symptom Manag. 2011;41(1):68-78

16. Tang ST, Huang EW, Liu TW, Rau KM, Hung YN, Wu SC. Propensity for home death among Taiwanese cancer decedents in 2001-2006, determined by services received at end of life. J Pain Symptom Manag. 2010;40(4):566-74.

17. Ke LS, Huang $X, O^{\prime}$ Connor M, Lee $S$. Nurses' views regarding implementing advance care planning for older people: a systematic review and synthesis of qualitative studies. J Clin Nurs. 2015;24(15-16):2057-73.

18. Chan HY, Ng JS, Chan KS, Ko PS, Leung DY, Chan CW, et al. Effects of a nurse-led post-discharge advance care planning programme for community-dwelling patients nearing the end of life and their family members: a randomised controlled trial. Int J Nurs Stud. 2018;87:26-33.

19. Cohen A, Nirenberg A. Current practices in advance care planning: implications for oncology nurses. Clin J Oncol Nurs. 2011;15(5):547-53.

20. Ryan D, Jezewski MA. Knowledge, attitudes, experiences, and confidence of nurses in completing advance directives: a systematic synthesis of three studies. J Nurs Res. 2012;20(2):131-41.

21. Zhou G, Stoltzfus JC, Houldin AD, Parks SM, Swan BA. Knowledge, attitudes, and practice behaviors of oncology advanced practice nurses regarding advanced care planning for patients with cancer. Oncol Nurs Forum. 2010; 37(6):E400-10.

22. Beckstrand RL, Collette J, Callister L, Luthy KE. Oncology nurses' obstacles and supportive behaviors in end-of-life care: providing vital family care. Oncol Nurs Forum. 2012;39(5):E398-406.

23. Thomas K, Lobo B. Advance Care Planning in End of Life Care: Oxford Scholarship Online; 2011. cited 2018

24. Jezewski MA, Meeker MA, Robillard I. What is needed to assist patients with advance directives from the perspective of emergency nurses. J Emerg Nurs. 2005;31(2):150-5

25. Keating NL, Landrum MB, Rogers SO Jr, Baum SK, Virnig BA, Huskamp HA, et al. Physician factors associated with discussions about end-of-life care. Cancer. 2010;116(4):998-1006

26. Kermel-Schiffman I, Werner P. Knowledge regarding advance care planning: a systematic review. Arch Gerontol Geriatr. 2017;73:133-42.

27. Lee ST. Guideline of clinical competence assessment. Taiwan: Elsevier Health Sciences; 2012.

28. Yu ML. Education test and evaluation. 3rd ed. Psychological: Taiwan; 2011.

29. Hsu SM, Hurng BS, Hungrng YT. The Taiwan behavior risk factor surveillance system: reliability analysis. Survey Reaearch - Method and Application. 2011; 26:123-59.

30. NHPCO. NHPCO Facts and Figures: Pediatric Palliative and Hospice Care in America. Alexandria, Virginia: NHPCO(National Hospice and Palliative Care Organization); 2015 [updated April, 2018; cited 2018 07/20]. Available from: https://www.nhpco.org/hospice-statistics-research-press-room/facts-hospiceand-palliative-care.

31. Teno J, Lynn J, Wenger N, Phillips RS, Murphy DP, Connors AF Jr, et al. Advance directives for seriously ill hospitalized patients: effectiveness with the patient self-determination act and the SUPPORT intervention. SUPPORT investigators. Study to understand prognoses and preferences for outcomes and risks of treatment. J Am Geriatr Soc. 1997;45(4):500-7.

32. welfare Moha. Patient Autonomy Act. 2018

33. Seymour J, Almack K, Kennedy S. Implementing advance care planning: a qualitative study of community nurses' views and experiences. BMC Palliat Care. 2010;9:4
34. Jezewski MA, Brown J, Wu YW, Meeker MA, Feng JY, Bu X. Oncology nurses' knowledge, attitudes, and experiences regarding advance directives. Oncol Nurs Forum. 2005;32(2):319-27.

35. Black K, Emmet C. Nurses' advance care planning communication: an investigation. Geriatr Nurs. 2006;27(4):222-7 quiz 8.

36. Shepherd J, Waller A, Sanson-Fisher R, Clark K, Ball J. Knowledge of, and participation in, advance care planning: a cross-sectional study of acute and critical care nurses' perceptions. Int J Nurs Stud. 2018;86:74-81.

\section{Publisher's Note}

Springer Nature remains neutral with regard to jurisdictional claims in published maps and institutional affiliations.
Ready to submit your research? Choose BMC and benefit from:

- fast, convenient online submission

- thorough peer review by experienced researchers in your field

- rapid publication on acceptance

- support for research data, including large and complex data types

- gold Open Access which fosters wider collaboration and increased citations

- maximum visibility for your research: over $100 \mathrm{M}$ website views per year

At $\mathrm{BMC}$, research is always in progress.

Learn more biomedcentral.com/submissions 